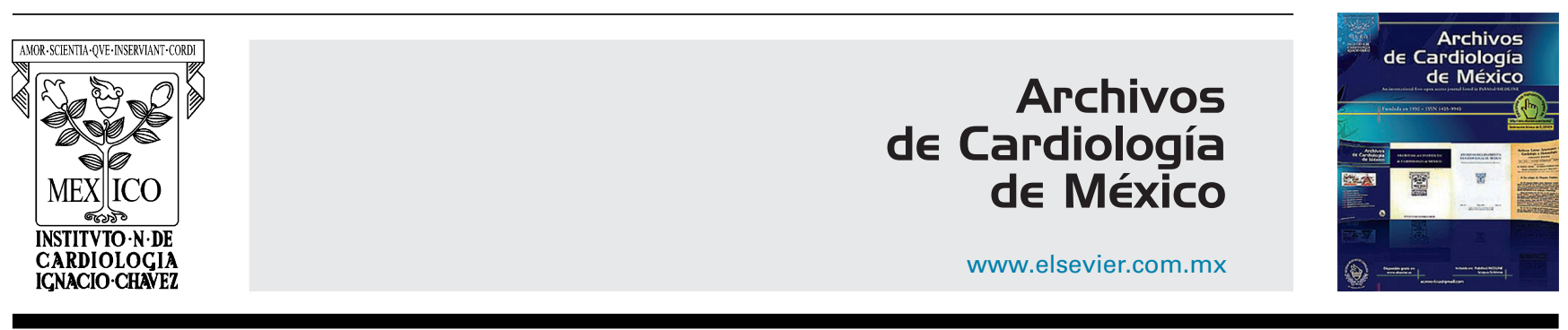

IMAGEN EN CARDIOLOGÍA

\title{
Extrusión de marcapasos normofuncionante a través de surco submamario
}

\section{Extrusion of a normally functioning pacemaker through the submammary sulcus}

\author{
José Werenitzky ${ }^{\mathrm{a}}$, Augusto Lépori ${ }^{\mathrm{a}, *}$, Matías Clavero ${ }^{\mathrm{a}}$, Marcelo Figueroa $^{\mathrm{b}}$, \\ Jorge Figueroa ${ }^{c}$ y José Luis Serra ${ }^{c}$

\footnotetext{
a Servicio de Cardiología, Sanatorio Allende Nueva Córdoba, Ciudad de Córdoba, Córdoba, Argentina

b Servicio de Cirugía Cardiovascular, Sanatorio Allende Nueva Córdoba, Ciudad de Córdoba, Córdoba, Argentina

c Servicio de Cardiología, Unidad de Arritmias y Marcapasos, Sanatorio Allende Nueva Córdoba, Ciudad de Córdoba, Córdoba, Argentina
}

Recibido el 26 de diciembre de 2015; aceptado el 17 de octubre de 2016

\begin{abstract}
Presentamos el caso de una mujer de 80 años, con antecedentes de diabetes mellitus tipo 2 e hipertensión arterial controladas adecuadamente, portadora de marcapasos (MP) bicameral en modo DDD debido a bloqueo auriculoventricular completo hace 12 años. Actualmente, acude al observar un cuerpo extraño en el surco submamario derecho, lugar donde había recibido tratamiento previo con antimicóticos tópicos por presentar signos inflamatorios con sospecha de micosis, sin realizar control del MP. Al momento de la consulta se encontraba normotensa, afebril, y con una frecuencia cardíaca de $60 \mathrm{lpm}$ debido a estimulación permanente de su MP, con ritmo sinusal basal. Al examen se objetivó el generador extruido a través del surco descripto, evidenciándose adecuada conexión con los electrodos (fig. 1). La radiografía de tórax mostraba el MP fuera de la cavidad torácica, con electrodos adecuadamente ubicados en aurícula y ventrículo derechos (fig. 2). Dada la contaminación del sistema, se realizó tratamiento
\end{abstract}

\footnotetext{
* Autor para correspondencia. Servicio de Cardiología (2. ${ }^{\circ}$ piso). Obispo Oro 42, Córdoba, Argentina, CP X5000BFB;

Teléfono celular: +5493513258661 ; Fax: +543514269209 .

Correo electrónico: aj1087@hotmail.com (A. Lépori).
}

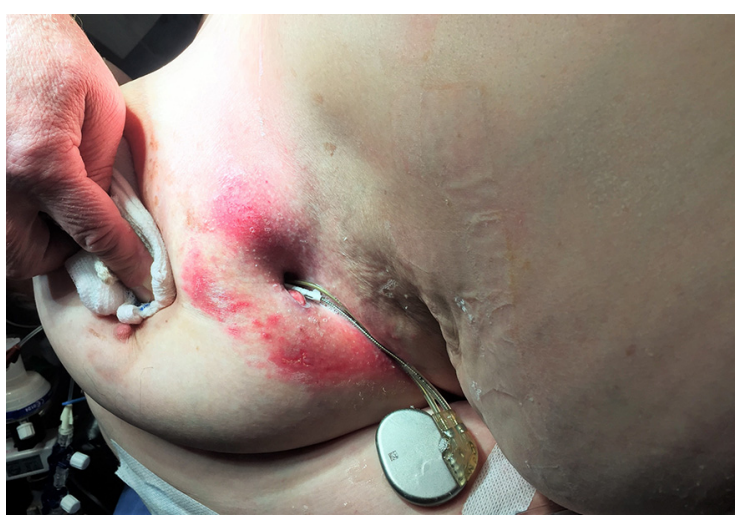

Figura 1 Generador y electrodos del marcapasos, surgiendo a través del surco submamario derecho.

antibiótico empírico y se decidió remplazar el sistema de estimulación endocárdico, tras extracción del mismo por esternotomía mediana, por uno epicárdico unicameral debido a la dependencia de la paciente a su sistema de estimulación. La paciente presentó buena evolución, y no mostró complicaciones durante 12 meses de seguimiento. 


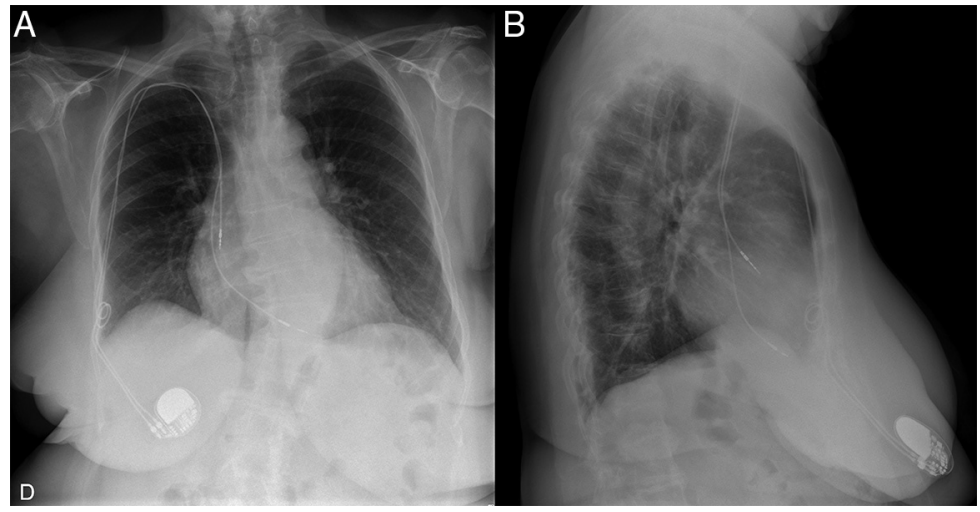

Figura 2 Radiografía de tórax en proyecciones anteroposterior (A) y lateral (B), donde se objetiva el generador del marcapasos en zona de la mama derecha.

La extrusión del generador de un MP es una complicación tardía, y se estima que su incidencia aproximada es del $1 \%$. Se produce debido a la necrosis tisular por presión, y suele darse entre otras causas por desplazamiento del generador (a veces no fijado) posterior al implante, lo cual permite la migración, y así la erosión de los tejidos blandos hasta emerger a través de la piel ${ }^{1}$. Suele presentarse en pacientes añosos, con escaso tejido celular subcutáneo, y diabéticos, en los cuales existe una predisposición a infecciones tanto cutáneas como del dispositivo ${ }^{2}$. Debido a que la extracción no era posible sin la colocación de un nuevo sistema de estimulación, se decidió remover el dispositivo infectado por esternotomía y el implante simultáneo de un MP epicárdico, ya que no se recomienda la utilización de sistemas endovenosos en este tipo de pacientes por el riesgo de endocarditis y sepsis ${ }^{3}$.

\section{Responsabilidades éticas}

Protección de personas y animales. Los autores declaran que para esta investigación no se han realizado experimentos en seres humanos ni en animales.

Confidencialidad de los datos. Los autores declaran que en este artículo no aparecen datos de pacientes.
Derecho a la privacidad y consentimiento informado. Los autores declaran que en este artículo no aparecen datos de pacientes.

\section{Financiación}

No se recibió patrocinio de ningún tipo para llevar a cabo este artículo.

\section{Conflicto de intereses}

Los autores declaran no tener ningún conflicto de intereses.

\section{Bibliografía}

1. Nichev J, Balabanski T. A case of total pacemaker extrusion. Europace. 2009;11:670.

2. Yuksel S, Demir S, Sahin M. Total extrusion of a normally functioning pacemaker. Tex Heart Inst J. 2012;39:156-7.

3. Baddour LM, Epstein AE, Erickson CC, et al. Update on cardiovascular implantable electronic device infections and their management: A scientific statement from the American Heart Association. Circulation. 2010;121:458-77. 